\title{
Gacyclidine improves the survival and reduces motor deficits in a mouse model of amyotrophic lateral sclerosis
}

\author{
Yannick N. Gerber ${ }^{1,2}$, Alain Privat ${ }^{1}$ and Florence E. Perrin ${ }^{1,2,3 *}$ \\ 1 Institute for Neurosciences of Montpellier (INM), INSERM U 1051, Montpellier, France \\ 2 "Integrative Biology of Neurodegeneration," IKERBASQUE Basque Foundation for Science, Neuroscience Department, University of the Basque Country, Bilbao, \\ Spain \\ 3 "Integrative Biology of Neuroregeneration," Faculty of Science, University of Montpellier 2, Montpellier, France
}

\section{Edited by:}

Ricardo Tapia, Universidad Nacional Autónoma de México, Mexico

Reviewed by:

Patrizia Longone, Fondazione Santa Lucia, Italy

Helene E. Hirbec, Institut of

Functional Genomics, France

\section{${ }^{*}$ Correspondence}

Florence E. Perrin, Institute for Neurosciences of Montpellier, INSERM U 1051, Saint-Eloi Hospital, 80 av., Augustin Fliche, 34091 Montpellier Cedex 05, France e-mail: florence.perrin@inserm.fr
Amyotrophic lateral sclerosis (ALS) is a fatal neurodegenerative disorder typified by a massive loss of motor neurons with few therapeutic options. The exact cause of neuronal degeneration is unknown but it is now admitted that ALS is a multifactorial disease with several mechanisms involved including glutamate excitotoxicity. More specifically, $\mathrm{N}$-methyl-D-aspartate (NMDA)-mediated cell death and impairment of the glutamate-transport has been suggested to play a key role in ALS pathophysiology. Thus, evaluating NMDAR antagonists is of high therapeutic interest. Gacyclidine, also named GK11, is a high affinity non-competitive NMDAR antagonist that may protect against motor neuron death in an ALS context. Moreover, GK11 presents a low intrinsic neurotoxicity and has already been used in two clinical trials for CNS lesions. In the present study, we investigated the influence of chronic administration of two doses of GK11 0.1 and $1 \mathrm{mg} / \mathrm{kg}$ ) on the survival and the functional motor activity of hSOD1G93A mice, an animal model of ALS. Treatment started at early symptomatic age (60 days) and was applied bi-weekly until the end stage of the disease. We first confirmed that functional alteration of locomotor activity was evident in the hSOD1 ${ }^{\mathrm{G} 93 \mathrm{~A}}$ transgenic female mice by 60 days of age. A low dose of GK11 improved the survival of the mice by $4.3 \%$ and partially preserved body weight. Improved life span was associated with a delay in locomotor function impairment. Conversely, the high dose treatment worsened motor functions. These findings suggest that chronic administration of GK11 beginning at early symptomatic stage may be beneficial for patients with ALS.

Keywords: GK11, NMDA receptor antagonist, ALS, survival, locomotion

\section{INTRODUCTION}

Amyotrophic lateral sclerosis (ALS) is a chronic neurodegenerative disease characterized by neuronal death of both lower and upper motoneurons in the spinal cord, the brain stem and the motor cortex. This chronic motor neuronopathy leads to progressive atrophy of skeletal muscles, paralysis and ultimately to death of the patients mainly due to respiratory failure [for review see (Turner et al., 2013)].

Pathogenesis and mechanisms of selective vulnerability of motoneurons in ALS are still largely unknown although, within the past two decades, it has been demonstrated that ALS is a complex multifactorial disease. Indeed many factors including protein misfolding, glutamate-mediated excitotoxicity, oxidative stress and impaired axonal transport may contribute to motoneuron death in ALS [for review see Robberecht and Philips (2013)]. An excessive stimulation of glutamate receptors induces excitotoxic processes; this phenomenon being largely implicated in both acute and chronic neurodegenerative diseases (Olney, 1989; Plaitakis and Constantakakis, 1993; Mehta et al., 2013), and in particular in ALS (Heath and Shaw, 2002; Bogaert et al., 2010). In the objective of translation to clinics, excitotoxicity is one of the key pharmacological targets as attested by the only FDA-approved drug, riluzole (2-amino-6-trifluoromethoxy benzothiazole) which is a modulator of excitatory neurotransmitters activity (including glutamate) (Bogaert et al., 2010). Glutamate interacts with a large range of specific transporters and receptors such as $\mathrm{N}$-methyl-D-aspartate receptors (NMDARs) (Mehta et al., 2013) and a promising, but so far overlooked therapeutic strategy, is to reduce excitotoxicity using NMDA receptor antagonist [for review see Spalloni et al. (2013)]. The low-affinity non-competitive NMDAR antagonist, memantine displayed encouraging results in $\mathrm{hSOD} 1^{\mathrm{G} 93 \mathrm{~A}}$ mice (Wang and Zhang, 2005; Joo et al., 2007), an ALS animal model. Clinical trials have shown that memantine is safe and well tolerated by ALS patients (de Carvalho et al., 2010; Levine et al., 2010) but no evidence of its efficacy had been reported yet.

Gacyclidine (GK11), a phencyclidine, is a non-competitive NMDA receptor antagonist, with a selective affinity for NR2B receptors, that had been shown to prevent glutamate-induced neuronal death in vitro and is less neurotoxic than other NMDA receptor antagonists (Hirbec et al., 2001; Vandame et al., 2007). Moreover, in vivo GK11 exhibits neuroprotective effects following organophosphorous nerve agents-induced convulsions (Bhagat et al., 2005) and following spinal cord injury (Feldblum et al., 
2000; Gaviria et al., 2000a,b; Kouyoumdjian et al., 2009; Lonjon et al., 2010).

In this study we have evaluated the effect of chronic treatment of two doses of GK11 on the survival and the locomotor function of hSOD1 ${ }^{\mathrm{G} 93 \mathrm{~A}}$ mice. We demonstrate a dose effect of GK11 on the survival of the mice, treatment with a low GK11 dose induced an increase in life span conversely to a high dose that reduced it. Moreover, treatment-induced increase in survival was associated with a reduction of locomotor function impairment whereas high dose treatment worsened the motor phenotype.

\section{MATERIALS AND METHODS ANIMALS}

Transgenic mice carrying the G93A human SOD1 mutation, B6SJL-Tg (SOD1-G93A) 1Gur/J (ALS mice, high copy number) were purchased from The Jackson Laboratory (Bar Harbor, ME, USA) and bred on a B6SJL background. Transgenic mice were identified by PCR and housed in controlled conditions (hygrometry, temperature and $12 \mathrm{~h}$ light/dark cycle); the environment was not modified over the course of the protocol. Only females were used and litter-matching between groups were done as much as possible. We carried out all animal experiments in accordance with the guidelines approved by the French Ministry of Agriculture and following the European Council directive (2010/63/UE). Every effort was made to minimize the number and suffering of animals. Age of death was defined as functional paralysis of both hindlimbs and a righting reflex $>20 \mathrm{~s}$. These criteria follow the commonly accepted guide lines for working on ALS mice (Leitner and Lutz, 2009; Solomon et al., 2011).

\section{GK11 TREATMENTS}

Twice a week, mice (transgenic and control) were intraperitoneally injected with either gacyclidine (two different concentrations; $1 \mathrm{mg} / \mathrm{kg}$ or $0.1 \mathrm{mg} / \mathrm{kg}$ ) (Neuréva, Montpellier, France) or $\mathrm{NaCl}$. The treatment doses were determined according to the following criteria: the dose of $1 \mathrm{mg} / \mathrm{kg}$ corresponds to the acute therapeutic dose in rat (Feldblum et al., 2000; Gaviria et al., 2000b) and we wanted to test the possible toxic effect of a chronic administration. Repeated administration of low dose of non-competitive NMDA receptor antagonists induces hyperlocomotion in rat (Wolf and Khansa, 1991; Loscher and Honack, 1992; Matsuoka et al., 2005). Injections were thus not done daily not only to reduce the risk of peritonitis but also to prevent possible interference of injections with behavioral tests. Treatment started at 60 days of age and was carried until the death of the animal. Number of mice: controls injected with GK11 $(0.1 \mathrm{mg} / \mathrm{Kg}, n=10 ; 1 \mathrm{mg} / \mathrm{Kg}, n=5)$ or $\mathrm{NaCl}(n=14)$; transgenic mice injected with GK11 $(0.1 \mathrm{mg} / \mathrm{Kg}, n=15 ; 1 \mathrm{mg} / \mathrm{Kg}$, $n=5)$ or $\mathrm{NaCl}(n=21)$.

\section{BEHAVIORAL ANALYSIS}

\section{Catwalk}

We used the CatWalk ${ }^{\mathrm{TM}}$ (Noldus, Wageningen, The Netherlands) to study dynamic and voluntarily walking patterns of the mice. As previously described (Gerber et al., 2012a) we selected amongst locomotor patterns, the "relative position" that corresponds to the distance between the placement of front and hind paws over one walking step. For data collection, six runs per animal were performed on a weekly basis from day 60 (just prior the first injection) and until animals were not able to correctly cross the walkway due to hindlimb paralysis. For each mouse, a minimum of three runs crossed at the same speed with 3-full step sequence patterns per run were recorded. To accustom the animals to the environment and thus to avoid bias due to stress, we placed transgenic and control littermates mice on the CatWalk 7 and 3 days prior to the first recording session. Catwalk analyses started before the first injection, the next behavioral session was done at least $72 \mathrm{~h}$ after treatment. Recordings were performed until the failure to obtain satisfactory paw patterns with the CatWalk analysis system due to hindlimb paralysis and thus absence of paw detection in the transgenic groups. Data analysis was done in collaboration with InnovationNet (Tiranges, France).

\section{Open field activity}

Spontaneous locomotor activity of mice was monitored in an open field test. Animals were placed in an empty test arena $(45 \times 45 \mathrm{~cm}$ box $)$ and movements automatically recorded. We analyzed the total distance $(\mathrm{cm})$ (Bioseb, Open field, Actitrack software, Vitrolles, France). Recording sessions started at P53 and until the end of life of the transgenic mice; analysis correspond to a weekly 8 min' sessions preceded by $2 \mathrm{~min}$ without recordings to avoid any bias due to stress. Open field test were performed on a weekly basis, $48 \mathrm{~h}$ after the injection. Recording sessions were performed until mice were unable to move in the test arena

\section{STATISTICAL ANALYSIS}

Kaplan Meier analysis and log-rank test were applied for survival curves (Figure 1A). Two ways ANOVA followed by TukeyKramer test was used for all analysis that consist on a combination of a treatment (at three different doses, $\mathrm{NaCl}$, GK11 $0.1 \mathrm{mg} / \mathrm{kg}$ and GK11 $1 \mathrm{mg} / \mathrm{kg}$ ) on two distinct genotypes over time (Figures 1B, 2B, 3A-C, 4). From 116 days onward transgenic and control mice could not be directly compared due to speed differences, moreover due to death GK11 $1 \mathrm{mg} / \mathrm{kg}$ treated transgenic mice were not included from P123 onwards. We thus used one way ANOVA followed by Tukey-Kramer test for Figure 3D and one way ANOVA followed by Mann-Whitney test for Figures 3E,F. For all analysis at P60 i.e., before the treatment started $t$-test was done (Figures 1A, A1). CatWalk data consist on replicates of a minimum of 3 and a maximum of 6 runs (same speed with 3 full step sequence) per animal in all cases these values were averaged. Experiments were designed to reach a $95 \%$ power to detect a $10 \%$ or greater difference between groups. We used GraphPad Prism version 5.03 (GraphPad software, CA, USA, and Minitab 15, Minitab Inc, USA).

\section{RESULTS}

\section{DOSE EFFECT OF GACYCLIDINE ON THE SURVIVAL OF THE MICE}

We first assessed the influence of a chronic treatment with GK11 $(0.1 \mathrm{mg} / \mathrm{kg})$, a non-competitive NMDA receptor antagonist, on the survival of hSOD ${ }^{\mathrm{G} 93 \mathrm{~A}}$ female mice. Animals treated with GK11 display an increased survival as compared to animals 

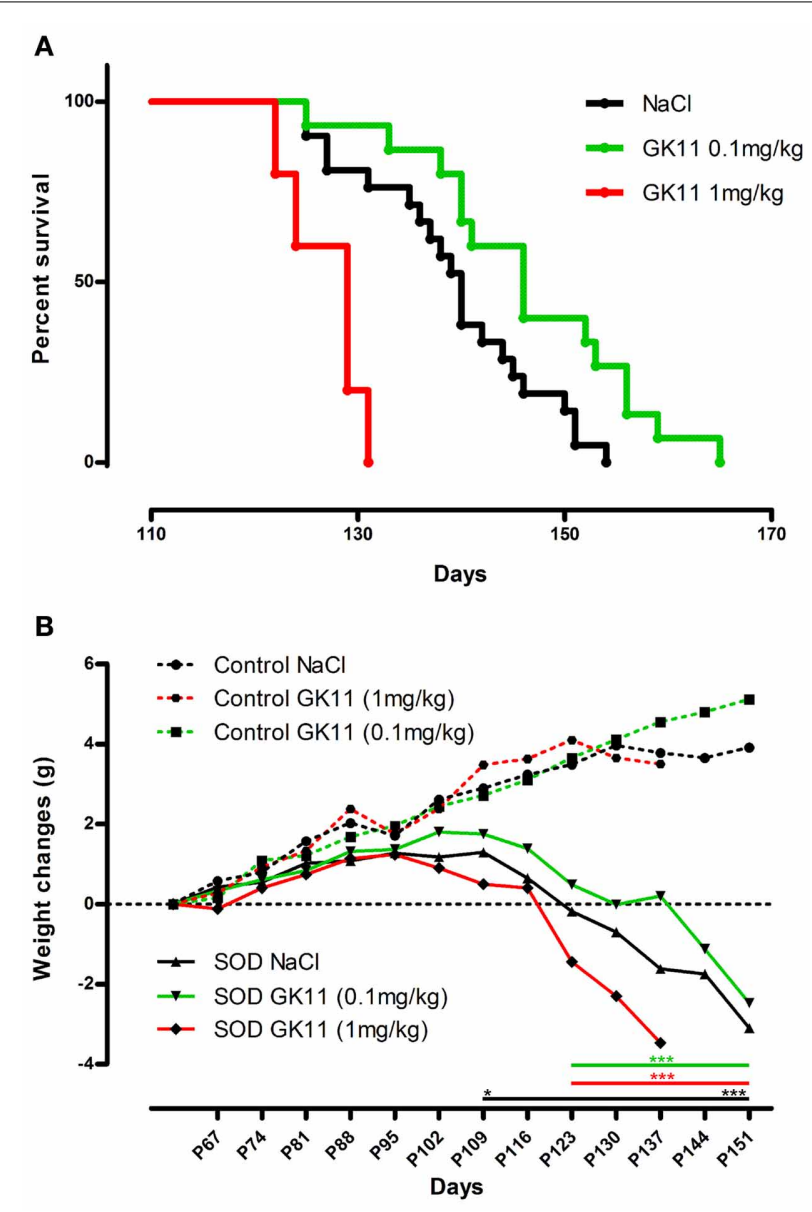

FIGURE 1 | Dose effect of Gacyclidine on hSOD1 ${ }^{\text {G93A }}$ mice survival and weight. (A) -Kaplan-Meier curves of hSOD1 ${ }^{\text {G93A }}$ mice injected i.p with $\mathrm{NaCl}(n=21)$, GK11 $0.1 \mathrm{mg} / \mathrm{kg}(n=15)$ or GK11 $1 \mathrm{mg} / \mathrm{kg}(n=5)$.

(B)-Weight changes (g) in control (dash line) and transgenic mice (continuous line) injected with $\mathrm{NaCl}$, GK11 $0.1 \mathrm{mg} / \mathrm{kg}$ or GK11.1 mg/kg. Two-ways ANOVA followed by Tukey-Kramer test $\left[F_{(10,695)}=96.18\right]$. Weight of $\mathrm{NaCl}$ treated controls and transgenics significantly differs from P109 whereas weight of GK11 (both doses) treated controls and transgenics significantly differ from P123. ${ }^{*} p<0.05$ and ${ }^{* * *} p<0.001$.

injected with $\mathrm{NaCl}$. Median survivals are indeed of 146 and 140 for mice injected with $\mathrm{GK} 11$ and $\mathrm{NaCl}$ respectively; this represent a significant $4.3 \%$ increase in life span (Kaplan Meier, $P$-value $=$ 0.0341) (Figure 1A).

To evaluate the possible toxicity margin of the molecule, we injected mice with a $1 \log$ higher GK11 concentration $(1 \mathrm{mg} / \mathrm{kg})$. Mice chronically injected with this high dose show a significant decrease in lifespan as compared to the littermates injected with $\mathrm{NaCl}$. Median survivals are indeed of 129 and 140 for mice injected with $\mathrm{GK} 11$ and $\mathrm{NaCl}$ respectively; this represents a significant $7.9 \%$ decrease in life span (Kaplan Meier, $P$-value $=0.006$ ) (Figure 1A).

Over the progression of the disease, transgenic mice lost weight due to muscular atrophy. We monitored body weight changes from $\mathrm{P} 60$ until death. $\mathrm{NaCl}$ injected transgenic mice weight differs significantly from those of the $\mathrm{NaCl}$ injected control group

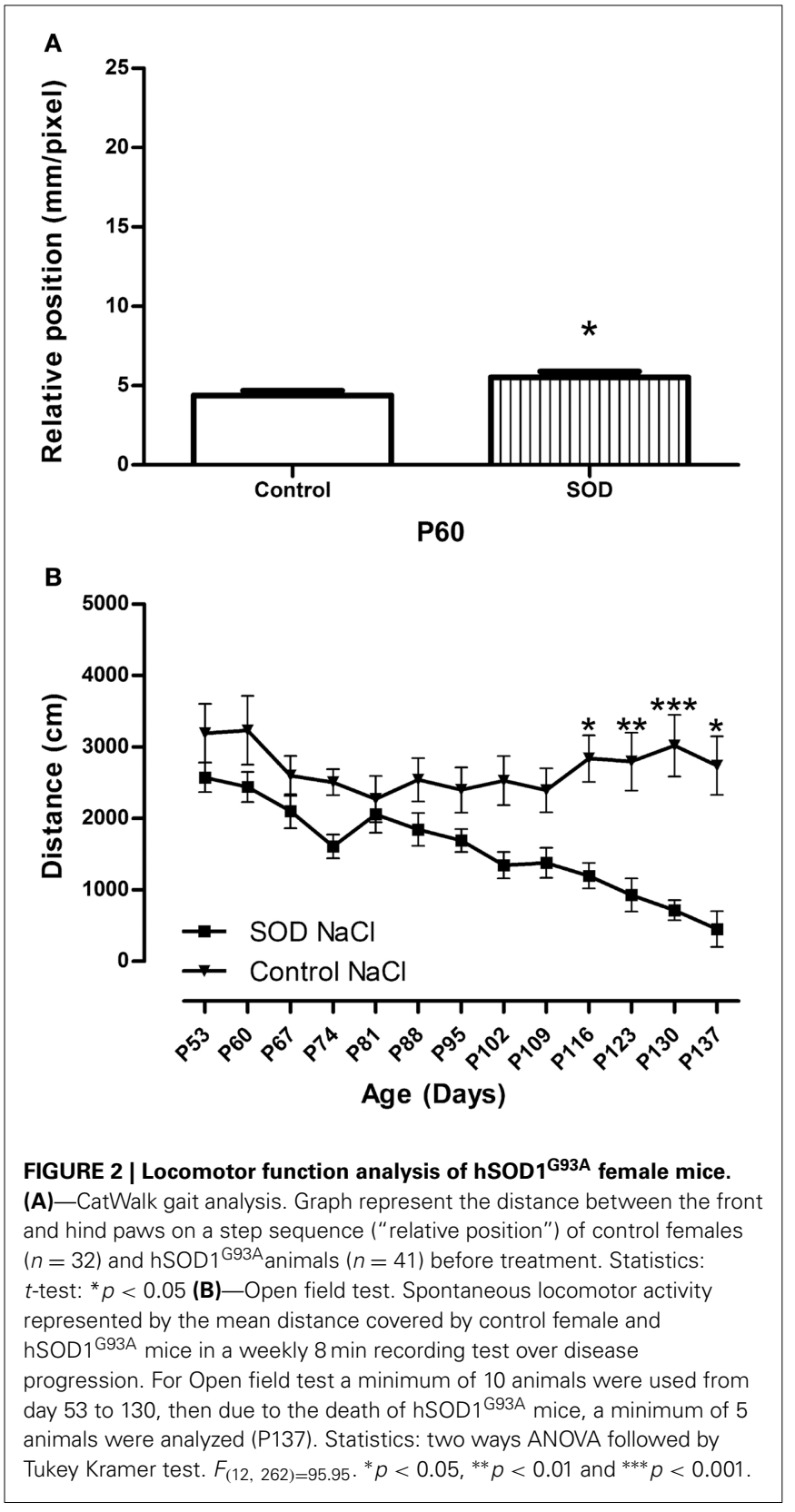

from P109 whereas weight of GK11 treated transgenic mice (both doses) is significantly different from GK11 treated control mice from P123 (Figure 1B). There is no effect of GK11 treatment on the body weight of control mice.

We thus evidence a beneficial effect of a chronic low dose of GK11 on the survival of hSOD1 ${ }^{\mathrm{G} 93 \mathrm{~A}}$ female mice whereas a high dose of GK11 has a detrimental effect.

\section{LOCOMOTOR FUNCTION IS ALTERED AT 60 DAYS OF AGE IN FEMALE hSOD1 G93A MICE}

In the perspective of translational studies, it is important to apply the therapeutic strategy at early symptomatic period. Experiments were done on female mice, it was thus mandatory to thoroughly characterize disease onset and progression in female 

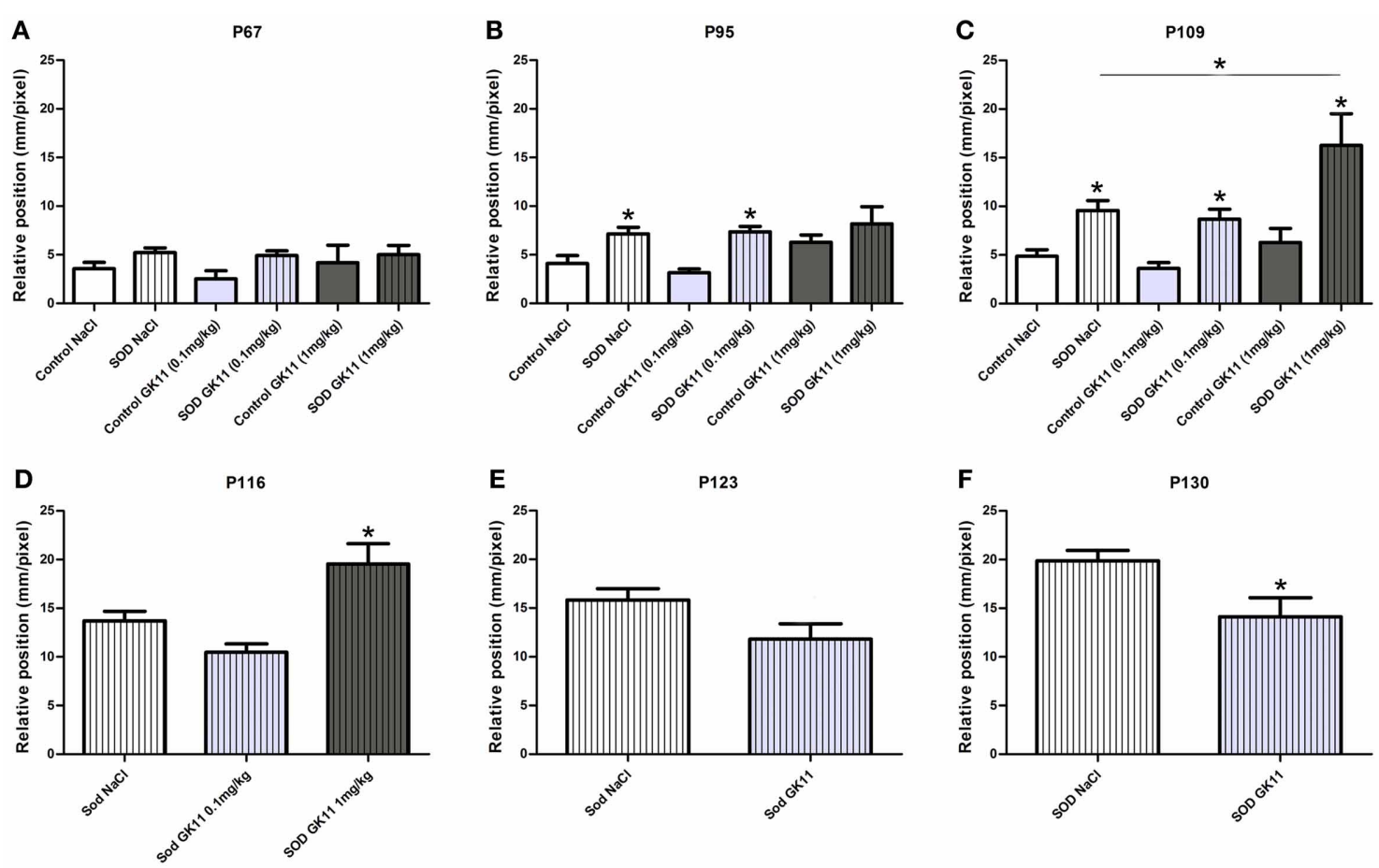

FIGURE 3 | Evaluation of Gacyclidine effects on hSOD1 ${ }^{\mathrm{G} 93 \mathrm{~A}}$ mice motor pattern: CatWalk gait analysis. Graphs represent the distance between the front and hind paws on a step sequence ("relative position"). (A-C) - control and hSOD1 ${ }^{\mathrm{G} 93 \mathrm{~A}}$ animals ( $\mathrm{NaCl}, \mathrm{GK} 110.1 \mathrm{mg} / \mathrm{kg}$ or GK11 $1 \mathrm{mg} / \mathrm{kg}$ treated)—Respectively at 67, 95, and, 109 days of age. (D) - hSOD1 ${ }^{\text {G93A }}$ animals ( $\mathrm{NaCl}, \mathrm{GK} 110.1 \mathrm{mg} / \mathrm{kg}$ or GK11 $1 \mathrm{mg} / \mathrm{kg}$ injected) at 116 days. (E, F) hSOD1 ${ }^{\mathrm{G} 93 \mathrm{~A}}$ animals ( $\mathrm{NaCl}$ or GK11 $0.1 \mathrm{mg} / \mathrm{kg}$ injected) at 123 and 130 days. A minimum of 4 and up to 24 animals per time point were analyzed from 67 to 116 days of age; recording were stopped for GK $111 \mathrm{mg} / \mathrm{kg}$ after P116 due to hindlimb paralysis. Then due to progression of the paralysis a minimum of 8 and up to 15 animals per time point were analyzed from 123 to 130 days of age. Statistics: $(\mathbf{A}-\mathbf{C})$ : two ways ANOVA followed by Tukey Kramer test. D: one way ANOVA followed by Tukey Kramer test. $(\mathbf{E}, \mathbf{F})$ : one way ANOVA followed by Mann-Whitney test. ${ }^{*} p<0.05$.

Combination of CatWalk and open field analysis allows an accurate description of motor alterations and permit to identify gait pattern alteration, and thus clinical onset of the disease, at 60 days of age. This is in agreement with our previous results in male hSOD1 ${ }^{\text {G93A }}$ mice (Gerber et al., 2012a) (Figure A1).

\section{INCREASED LIFE SPAN CORRELATED WITH DELAYED MOTOR DEFICITS}

We then used the CatWalk system to tentatively correlate the effects of the drug on the lifespan with modification of disease onset and/or progression of the disease; we compared locomotor functions of transgenic hSOD1 ${ }^{\mathrm{G} 93 \mathrm{~A}}$ females injected with either GK11 $(0.1 \mathrm{mg} / \mathrm{kg}$ or $1 \mathrm{mg} / \mathrm{kg})$ or $\mathrm{NaCl}$. In parallel, we evaluated whether GK11 had an effect on non-transgenic animal by comparing treated versus $\mathrm{NaCl}$ injected control mice.

From 67 days to 109 days, the relative position is identical in transgenic groups injected with GK11 $0.1 \mathrm{mg} / \mathrm{kg}$ or $1 \mathrm{mg} / \mathrm{kg}$ compared to transgenic mice injected with $\mathrm{NaCl}$. Controls animals of all groups (GK11 $0.1 \mathrm{mg} / \mathrm{kg}, 1 \mathrm{mg} / \mathrm{kg}$ or $\mathrm{NaCl}$ ) remain stable over the same period. However, transgenic mice $(0.1 \mathrm{mg} / \mathrm{kg}$ and $\mathrm{NaCl}$ ) show an alteration of the motor pattern when compared to their respective controls that increased from 95 to 109 days of age. At 109 days, transgenic mice injected with GK11 at high concentration show a critically altered phenotype compared not only to controls but also to the transgenic group injected with $\mathrm{NaCl}$ (Figures 3A-C). From 116 days onward, due to hindlimb 

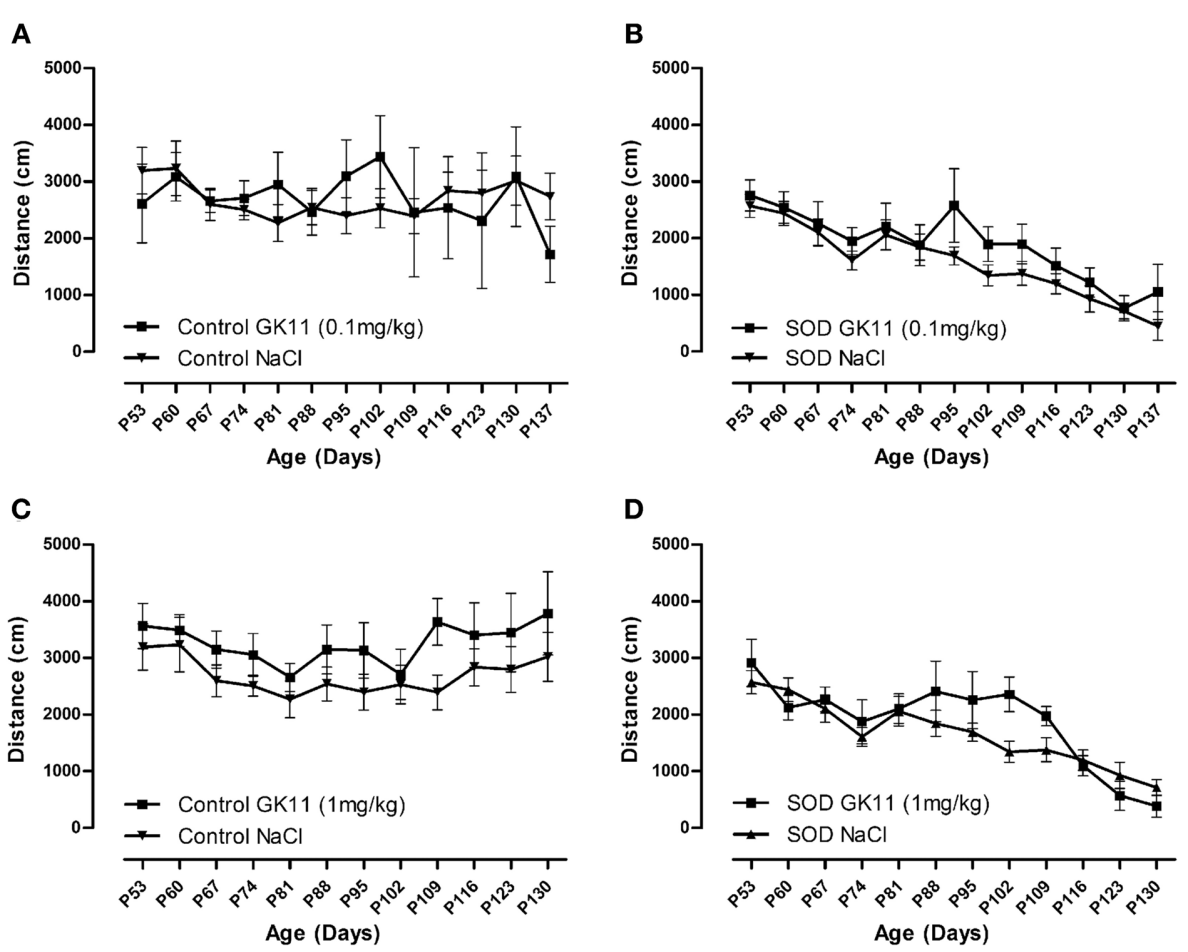

D

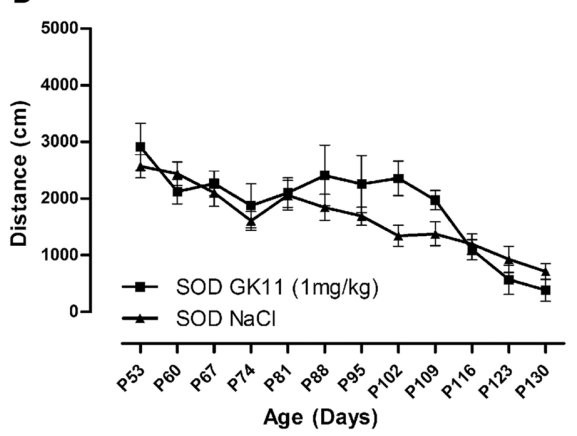

FIGURE 4 | Evaluation of Gacyclidine effects on the spontaneous motor activity of hSOD1 ${ }^{\text {G93A }}$ mice: Open Field analysis. Spontaneous locomotor activity represented by the mean distance covered by female controls and hSOD $1^{\text {G93A }}$ mice in a weekly 8 min recording test over disease progression

included. (A,B) — Control and hSOD1 ${ }^{\mathrm{G} 93 \mathrm{~A}}$ mice injected with $\mathrm{NaCl}$ or GK11 $0.1 \mathrm{mg} / \mathrm{kg}$. (C,D) - Control and hSOD1 ${ }^{\mathrm{G} 93 \mathrm{~A}}$ mice injected with $\mathrm{NaCl}$ or GK11 $1 \mathrm{mg} / \mathrm{kg}$. A minimum of 5 animals were analyzed per time point. Statistics: two ways ANOVA followed by Tukey Kramer test.

paralysis, transgenic and control mice do not achieve the CatWalk test at the same speed and thus, referring to Clarke's et al. study (Clarke and Still, 1999), cannot be compared. We thus analyzed separately hSOD1 ${ }^{\mathrm{G} 93 \mathrm{~A}}$ and control mice. At 116 days, mice injected with GK11 $1 \mathrm{mg} / \mathrm{kg}$ show an altered phenotype compared to the $\mathrm{NaCl}$ injected mice (Figure 3D). No satisfactory recording sessions were obtained for the GK11 $1 \mathrm{mg} / \mathrm{kg}$ from P123 onwards (Figures 3E,F). GK11 $0.1 \mathrm{mg} / \mathrm{kg}$ treated mice exhibit a reduction of locomotor function impairment compared to the transgenic $\mathrm{NaCl}$ group at $\mathrm{P} 130$ (Figure 3F). No difference between control groups were seen over the same period (data not shown). These results suggest that treatment with a low dose of GK11 induces a slight but significant delay in hindlimb paralysis progression. Oppositely, treatment with a high dose of GK11 worsened the motor pattern.

We used an open field system to measure the spontaneous locomotor activity of control and transgenic mice. No difference has been noted in the mean crossed distances when we compared both GK11 doses $(0.1$ and $1 \mathrm{mg} / \mathrm{kg})$ and $\mathrm{NaCl}$ injected mice for both control and transgenic groups (Figures 4A-D).

\section{DISCUSSION}

Glutamate mediated excitotoxicity is involved in ALS pathogenesis (Foran and Trotti, 2009) and several studies have evaluated the pharmacological profile of a number of molecules acting on glutamate release and transport [for review (Corona

et al., 2007; Bogaert et al., 2010)]. Gacyclidine (GK11), a noncompetitive NMDA receptor antagonist, has already been used in the clinics (Hirbec et al., 2001; Tadie et al., 2003; Lepeintre et al., 2004) and a single GK11 dose of $1 \mathrm{mg} / \mathrm{kg}$ has demonstrated neuroprotective effects on a model of photochemical spinal cord injury (Gaviria et al., 2000b). Chronic GK11 administration has never been reported. In view of these data, we decided to analyze the impact of a chronic treatment of GK11 on the survival and locomotor activity of hSOD1 ${ }^{\mathrm{G} 93 \mathrm{~A}}$ mice.

Our study clearly shows a dose response effect; indeed although a high GK11 dose is detrimental by shortening the life span of the mice by $7.9 \%$, a low dose induces a $4.3 \%$ increase in survival vs. controls. Moreover, this increased life span is associated with a reduction in walking pattern deficits whereas high dose treatment worsened the motor phenotype.

\section{GENDER EFFECTS ON SURVIVAL AND FUNCTIONAL DEFICITS IN THE SOD1 ${ }^{\text {G93A }}$ MOUSE MODEL OF ALS}

We have recently carried out a thorough analysis analyses of survival and motor function in hSOD $1^{\mathrm{G} 93 \mathrm{~A}}$ male mice (Gerber et al., 2012a,b). For the present study we have used females. Transgenic females survive significantly longer than males; median survivals were of 129 and 140 days for males and females respectively. Comparison with a previous study (Heiman-Patterson et al., 2005) attests for the stability of this mouse model; indeed 
reported life span was of 128 and 133 days for males and females respectively.

We have evaluated locomotor function of female hSOD1 ${ }^{\mathrm{G} 93 \mathrm{~A}}$ mice using the same combination of dynamic walking patterns and spontaneous motor activity analysis as previously done with males (Gerber et al., 2012a). As for males, we detect early functional deficits that confirm symptoms onset at 60 days of age, i.e., 20 days earlier than previously described (Figure A1). Indeed, dynamic gait analysis using the CatWalk system demonstrates alteration in gait pattern for both males and females from 60 days onwards. Spontaneous motor activity evaluated with an open field highlighted a decrease in the mean distance covered by transgenic animals as compared to their control littermate from 116 days onwards for females as compared to 102 days of age onwards for males (Gerber et al., 2012a). This difference may reflect gender-specific mechanism of synaptic impairment since a recent study demonstrated sexual dimorphism in the decline of the presynaptic machinery at an early symptomatic stage (Naumenko et al., 2011). Mean survival of hSOD1 ${ }^{\mathrm{G} 93 \mathrm{~A}}$ mice is of 140 days for female as compared to 129 days for males (Gerber et al., 2012a), however, even if female mice survive longer than male counterparts, early motor symptoms impairment are detected at 60 days of age in both gender.

\section{ANTIGLUTAMATE DRUGS}

One of the popular hypothesis regarding mechanisms involved in ALS is that an excessive activation of glutamate receptors may be responsible for motoneuron death (Corona et al., 2007). NMDA receptors are known for their permeability to cations and in particular to calcium; their over activation leading to excitoxic phenomenon. Recent findings have shown that subtypes of AMPA receptors, that either do not express the GluR2 subunit or express an edited form of this subunit, present a similar permeability to calcium than NMDA receptors (Van Den Bosch et al., 2000; Kawahara et al., 2006; Corona et al., 2007). These AMPA receptor subtypes are widely expressed in motoneurons and are therefore involved in excitotoxic processes (Carriedo et al., 1996; Gerardo-Nava et al., 2013). However, modulating AMPA excitoxicity mediated pathway is mostly ineffective in clinical trials and induce various side effect (such as dizziness and Ataxia) [for review see (Chang et al., 2012)]. Nevertheless, perampanel, a non-competitive AMPA receptor antagonist to AMPAR is very promising in the treatment of epilepsy (Rogawski, 2011). Several antiglutamate drugs have been evaluated in ALS [for review see (Gibson and Bromberg, 2012)]. Riluzole is the only approved treatment and prolongs median survival by about 2 to 3 months in ALS patients (Miller et al., 2012) and by $10.5 \%$ in mice (Gurney et al., 1996). Riluzole induces an inhibition of glutamate release and modulation of both alpha-amino3-hydroxy-5-methyl-4-isoxazolepropionic acid (AMPA) and Nmethyl-d-aspartate (NMDA) receptors (Jin et al., 2010; Cifra et al., 2013). However, Riluzole displays other diverse and multiple non-specific pharmacological properties (Cheah et al., 2010) that may cause adverse effects such as nausea, asthenia and raised alanine transferase (Miller et al., 2012). As recently pinpointed (Spalloni et al., 2013) the role of NMDA receptors activation in ALS has not received much attention, even if a low affinity non-competitive NMDAR antagonist, memantine, has shown promising results in an ALS animal model. In this context, evaluations of new therapeutic agents are of utmost importance. GK11, a high affinity uncompetitive NMDAR antagonist, presents a low intrinsic neurotoxicity, paucity of side effects attributed to its selectivity for NR2 B containing receptors (Vandame et al., 2007). No interaction was found with glutamatergic AMPA, kainate, or $\sigma 1$ and $\sigma 2$ receptors (Hirbec et al., 2001).

In our study, early symptomatic (starting at P60) bi-weekly chronic administration of a low dose of GK11 $(0.1 \mathrm{mg} / \mathrm{kg})$ yields a $4.3 \%$ increase in the life span of the female hSOD1 ${ }^{\mathrm{G} 93 \mathrm{~A}}$ mice. These results are similar to the effects of memantine (Wang and Zhang, 2005; Joo et al., 2007). Conversely to memantine (Joo et al., 2007), increase in survival induced by GK11 is associated with a significant protective effect on locomotor deterioration at the end stage of the disease. Of particular interest is the fact that, to-date, GK11 is the most specific NMDA receptor antagonist efficient in an animal model of ALS, thus definitely pinpointing the involvement of this receptor in the pathogenesis of the disease. High dose GK11 treatment leads to a decrease in the life span of female hSOD1 ${ }^{\mathrm{G} 93 \mathrm{~A}}$ associated to a more abrupt development of motor symptoms and hindlimb paralysis. Importantly, high dose drug treatment has no effect on weight loss, CatWalk or open field performances in the control group as reported in a recent study in rats undergoing an acute treatment (Vandame et al., 2013). This toxic side effect might reflect an induction of specific cascade events in the SOD context.

In conclusion, we demonstrate here that a chronic administration (starting at early symptomatic stage) of a non-competitive NMDA receptors antagonist significantly increases the survival of a mouse model of ALS. Indeed, a chronic low dose of GK11 prolongs the life span and reduces weight loss and motor deficits in hSOD ${ }^{\mathrm{G} 93 \mathrm{~A}}$ female mice. These results, combined with those from previous studies on CNS injury, demonstrating in patients a relative efficacy and the absence of side effects (Tadie et al., 2003; Lepeintre et al., 2004), suggest that low dose of GK11 could be used as a new and effective NMDA receptor antagonist for ALS patients.

\section{AUTHOR CONTRIBUTIONS}

Yannick N. Gerber: study conception and design, acquisition of data, analysis and interpretation of data and drafting of manuscript. Alain Privat: study conception and design and critical revision. Florence E. Perrin: study conception and design, analysis and interpretation of data and critical revision.

\section{ACKNOWLEDGMENTS}

The authors acknowledge J.C. Sabourin for his participation in management of the mouse colony, P. Villette, InnovationNet, for his great contribution in the analysis of the CatWalk data and H. N. Noristani for his contribution in the statistical analysis. This study was supported by the Spanish Government, Plan Nacional de I+D+I 2008-2011 and ISCIII - Subdireccion General de Evaluacion y Fomento de la Investigacion [PI10/00709 to Florence E. Perrin], the Basque Government, Fondo Comun de Cooperacion Aquitania-Euskadi and Proyectos de Investigacion 
Sanitaria [to Florence E. Perrin] and the Association "Demain Debout Aquitaine" [to Yannick N. Gerber].

\section{REFERENCES}

Bhagat, Y. A., Obenaus, A., Hamilton, M. G., Mikler, J., and Kendall, E. J. (2005). Neuroprotection from soman-induced seizures in the rodent: evaluation with diffusion- and T2-weighted magnetic resonance imaging. Neurotoxicology 26, 1001-1013. doi: 10.1016/j.neuro.2005.04.006

Bogaert, E., d'Ydewalle, C., and Van Den Bosch, L. (2010). Amyotrophic lateral sclerosis and excitotoxicity: from pathological mechanism to therapeutic target. CNS Neurol. Disord. Drug Targets 9, 297-304. doi: 10.2174/187152710791292576

Carriedo, S. G., Yin, H. Z., and Weiss, J. H. (1996). Motor neurons are selectively vulnerable to AMPA/kainate receptor-mediated injury in vitro. J. Neurosci. 16, 4069-4079.

Chang, P. K., Verbich, D., and McKinney, R. A. (2012). AMPA receptors as drug targets in neurological disease-advantages, caveats, and future outlook. Eur. J. Neurosci. 35, 1908-1916. doi: 10.1111/j.1460-9568.2012. 08165.x

Cheah, B. C., Vucic, S., Krishnan, A. V., and Kiernan, M. C. (2010). Riluzole, neuroprotection and amyotrophic lateral sclerosis. Curr. Med. Chem. 17, 1942-1199. doi: 10.2174/092986710791163939

Cifra, A., Mazzone, G. L., and Nistri, A. (2013). Riluzole: what it does to spinal and brainstem neurons and how it does it. Neuroscientist 19, 137-144. doi $10.1177 / 1073858412444932$

Clarke, K. A., and Still, J. (1999). Gait analysis in the mouse. Physiol. Behav. 66, 723-729. doi: 10.1016/S0031-9384(98)00343-6

Corona, J. C., Tovar-y-Romo, L. B., and Tapia, R. (2007). Glutamate excitotoxicity and therapeutic targets for amyotrophic lateral sclerosis. Expert Opin. Ther Targets 11, 1415-1428. doi: 10.1517/14728222.11.11.1415

de Carvalho, M., Pinto, S., Costa, J., Evangelista, T., Ohana, B., and Pinto, A. (2010). A randomized, placebo-controlled trial of memantine for functional disability in amyotrophic lateral sclerosis. Amyotroph. Lateral Scler. 11, 456-460. doi: 10.3109/17482968.2010.498521

Feldblum, S., Arnaud, S., Simon, M., Rabin, O., and D’Arbigny, P. (2000). Efficacy of a new neuroprotective agent, gacyclidine, in a model of rat spinal cord injury. J. Neurotrauma 17, 1079-1093. doi: 10.1089/neu.2000.17.1079

Foran, E., and Trotti, D. (2009). Glutamate transporters and the excitotoxic path to motor neuron degeneration in amyotrophic lateral sclerosis. Antioxid. Redox Signal. 11, 1587-1602. doi: 10.1089/ars.2009.2444

Gaviria, M., Privat, A., d'Arbigny, P., Kamenka, J., Haton, H., and Ohanna, F. (2000a). Neuroprotective effects of a novel NMDA antagonist, Gacyclidine, after experimental contusive spinal cord injury in adult rats. Brain Res. 874, 200-209. doi: 10.1016/S0006-8993(00)02581-6

Gaviria, M., Privat, A., d'Arbigny, P., Kamenka, J. M., Haton, H., and Ohanna, F. (2000b). Neuroprotective effects of gacyclidine after experimental photochemical spinal cord lesion in adult rats: dose-window and time-window effects. J. Neurotrauma 17, 19-30. doi: 10.1089/neu.2000.17.19

Gerardo-Nava, J., Mayorenko, I. I., Grehl, T., Steinbusch, H. W., Weis, J., and Brook, G. A. (2013). Differential pattern of neuroprotection in lumbar, cervical and thoracic spinal cord segments in an organotypic rat model of glutamate-induced excitotoxicity. J. Chem. Neuroanat. 53, 11-17. doi: 10.1016/j.jchemneu.2013.09.007

Gerber, Y. N., Sabourin, J. C., Rabano, M., Vivanco, M., and Perrin, F. E. (2012a). Early functional deficit and microglial disturbances in a mouse model of amyotrophic lateral sclerosis. PLoS ONE 7:e36000. doi: 10.1371/journal.pone. 0036000

Gerber, Y. N., Sabourin, J. C., Hugnot, J. P., and Perrin, F. E. (2012b). Unlike physical exercise, modified environment increases the lifespan of SOD1G93A mice however both conditions induce cellular changes. PLoS ONE 7:e45503. doi: 10.1371/journal.pone.0045503

Gibson, S. B., and Bromberg, M. B. (2012). Amyotrophic lateral sclerosis: drug therapy from the bench to the bedside. Semin. Neurol. 32, 173-178. doi: $10.1055 / \mathrm{s}-0032-1329193$

Gurney, M. E., Cutting, F. B., Zhai, P., Doble, A., Taylor, C. P., Andrus, P. K., et al. (1996). Benefit of vitamin E, riluzole, and gabapentin in a transgenic model of familial amyotrophic lateral sclerosis. Ann. Neurol. 39, 147-157. doi: 10.1002/ana.410390203
Heath, P. R., and Shaw, P. J. (2002). Update on the glutamatergic neurotransmitter system and the role of excitotoxicity in amyotrophic lateral sclerosis. Muscle Nerve 26, 438-458. doi: 10.1002/mus.10186

Heiman-Patterson, T. D., Deitch, J. S., Blankenhorn, E. P., Erwin, K. L., Perreault, M. J., Alexander, B. K., et al. (2005). Background and gender effects on survival in the $\mathrm{TgN}$ (SOD1-G93A) 1Gur mouse model of ALS. J. Neurol. Sci. 236, 1-7. doi: $10.1016 /$ j.jns.2005.02.006

Hirbec, H., Gaviria, M., and Vignon, J. (2001). Gacyclidine: a new neuroprotective agent acting at the N-methyl-D-aspartate receptor. CNS Drug Rev. 7, 172-198. doi: 10.1111/j.1527-3458.2001.tb00194.x

Jin, L. J., Schlesinger, F., Song, Y. P., Dengler, R., and Krampfl, K. (2010). The interaction of the neuroprotective compounds riluzole and phenobarbital with AMPA-type glutamate receptors: a patch-clamp study. Pharmacology 85, 54-62. doi: $10.1159 / 000268641$

Joo, I. S., Hwang, D. H., Seok, J. I., Shin, S. K., and Kim, S. U. (2007). Oral administration of memantine prolongs survival in a transgenic mouse model of amyotrophic lateral sclerosis. J. Clin. Neurol. 3, 181-186. doi: 10.3988/jcn.2007.3.4.181

Kawahara, Y., Sun, H., Ito, K., Hideyama, T., Aoki, M., Sobue, G., et al. (2006). Underediting of GluR2 mRNA, a neuronal death inducing molecular change in sporadic ALS, does not occur in motor neurons in ALS1 or SBMA. Neurosci. Res. 54, 11-14. doi: 10.1016/j.neures.2005.09.006

Kouyoumdjian, P., Lonjon, N., Prieto, M., Haton, H., Privat, A., Asencio, G., et al. (2009). A remotely controlled model of spinal cord compression injury in mice: toward real-time analysis. J. Neurosurg. Spine 11, 461-470. doi: 10.3171/2009.4.SPINE0979

Leitner, M. M., and Lutz, S. C. (2009). Working With ALS Mice in Guidelines for Preclinical Testing and Colony Management. Bar Harbor, ME: The Jackson Laboratory; Cambridge, MA: Prize 4Life, 1-21.

Lepeintre, J. F., D’Arbigny, P., Mathe, J. F., Vigue, B., Loubert, G., Delcour, J., et al. (2004). Neuroprotective effect of gacyclidine. A multicenter double-blind pilot trial in patients with acute traumatic brain injury. Neuro-Chirurgie 50(2-3 Pt 1), 83-95.

Levine, T. D., Bowser, R., Hank, N., and Saperstein, D. A. (2010). Pilot trial of memantine and riluzole in ALS: correlation to CSF biomarkers. Amyotroph. Lateral Scler. 11, 514-519. doi: 10.3109/17482968.2010.513052

Lonjon, N., Kouyoumdjian, P., Prieto, M., Bauchet, L., Haton, H., Gaviria, M., et al. (2010). Early functional outcomes and histological analysis after spinal cord compression injury in rats. J. Neurosurg. Spine 12, 106-113. doi: 10.3171/2009.7.SPINE0989

Loscher, W., and Honack, D. (1992). The behavioural effects of MK801 in rats: involvement of dopaminergic, serotonergic and noradrenergic systems. Eur. J. Pharmacol. 215, 199-208. doi: 10.1016/0014-2999(92) 90029-4

Matsuoka, T., Sumiyoshi, T., Tanaka, K., Tsunoda, M., Uehara, T., Itoh, H., et al. (2005). NC-1900, an arginine-vasopressin analogue, ameliorates social behavior deficits and hyperlocomotion in MK-801-treated rats: therapeutic implications for schizophrenia. Brain Res. 1053, 131-136. doi: 10.1016/j.brainres. 2005.06.035

Mehta, A., Prabhakar, M., Kumar, P., Deshmukh, R., and Sharma, P. L. (2013). Excitotoxicity: bridge to various triggers in neurodegenerative disorders. Eur. J. Pharmacol. 698, 6-18. doi: 10.1016/j.ejphar.2012.10.032

Miller, R. G., Mitchell, J. D., and Moore, D. H. (2012). Riluzole for amyotrophic lateral sclerosis (ALS)/motor neuron disease (MND). Cochrane Database Syst. Rev. 3, CD001447. doi: 10.1002/14651858.CD001447.pub3

Naumenko, N., Pollari, E., Kurronen, A., Giniatullina, R., Shakirzyanova, A. Magga, J., et al. (2011). Gender-specific mechanism of synaptic impairment and its prevention by GCSF in a mouse model of ALS. Front. Cell. Neurosci. 5:26. doi: $10.3389 /$ fncel.2011.00026

Olney, J. W. (1989). Glutamate, a neurotoxic transmitter. J. Child Neurol. 4, 218-226. doi: 10.1177/088307388900400315

Plaitakis, A., and Constantakakis, E. (1993). Altered metabolism of excitatory amino acids, $\mathrm{N}$-acetyl-aspartate and $\mathrm{N}$-acetyl-aspartyl-glutamate in amyotrophic lateral sclerosis. Brain Res. Bull. 30, 381-386. doi: 10.1016/03619230(93)90269-H

Robberecht, W., and Philips, T. (2013). The changing scene of amyotrophic lateral sclerosis. Nat. Rev. Neurosci. 14, 248-264. doi: 10.1038/nrn3430

Rogawski, M. A. (2011). Revisiting AMPA receptors as an antiepileptic drug target. Epilepsy Curr. 11, 56-63. doi: 10.5698/1535-7511-11.2.56 
Solomon, J. A., Tarnopolsky, M. A., and Hamadeh, M. J. (2011). One universal common endpoint in mouse models of amyotrophic lateral sclerosis. PLoS ONE 6:e20582. doi: 10.1371/journal.pone.0020582

Spalloni, A., Nutini, M., and Longone, P. (2013). Role of the N-methyl-d-aspartate receptors complex in amyotrophic lateral sclerosis. Biochim. Biophys. Acta 1832, 312-322. doi: 10.1016/j.bbadis.2012.11.013

Tadie, M., Gaviria, M., Mathe, J.-F., Menthonenex, P., Loubert, G., Lagarrigue, J., et al. (2003). Early care and treatment with a neuroprotective drug, gacyclidine, in patients with acute spinal cord injury. Rachis 15, 363-376.

Turner, M. R., Hardiman, O., Benatar, M., Brooks, B. R., Chio, A., de Carvalho, M., et al. (2013). Controversies and priorities in amyotrophic lateral sclerosis. Lancet Neurol. 12, 310-322. doi: 10.1016/S1474-4422(13)70036-X

Van Den Bosch, L., Vandenberghe, W., Klaassen, H., Van Houtte, E., and Robberecht, W. (2000). Ca(2+)-permeable AMPA receptors and selective vulnerability of motor neurons. J. Neurol. Sci. 180, 29-34. doi: 10.1016/S0022510X(00)00414-7

Vandame, D., Desmadryl, G., Becerril Ortega, J., Teigell, M., Crouzin, N., Buisson, A., et al. (2007). Comparison of the pharmacological properties of GK11 and MK801, two NMDA receptor antagonists: towards an explanation for the lack of intrinsic neurotoxicity of GK11. J. Neurochem. 103, 1682-1696. doi: 10.1111/j.1471-4159.2007.04925.x

Vandame, D., Ulmann, L., Teigell, M., Cappelini-Prieto, M., Vignon, J., Privat, A., et al. (2013). Development of NMDARs antagonists with reduced neurotoxic side effects: a study on GK11. PLOS ONE 8:e81004. doi: 10.1371/journal.pone.0081004
Wang, R., and Zhang, D. (2005). Memantine prolongs survival in an amyotrophic lateral sclerosis mouse model. Eur. J. Neurosci. 22, 2376-2380. doi: 10.1111/j.1460-9568.2005.04431.x

Wolf, M. E., and Khansa, M. R. (1991). Repeated administration of MK-801 produces sensitization to its own locomotor stimulant effects but blocks sensitization to amphetamine. Brain Res. 562, 164-168. doi: 10.1016/00068993(91)91202-C

Conflict of Interest Statement: The authors declare that the research was conducted in the absence of any commercial or financial relationships that could be construed as a potential conflict of interest.

Received: 30 July 2013; accepted: 13 December 2013; published online: 27 December 2013

Citation: Gerber YN, Privat A and Perrin FE (2013) Gacyclidine improves the survival and reduces motor deficits in a mouse model of amyotrophic lateral sclerosis. Front. Cell. Neurosci. 7:280. doi: 10.3389/fncel.2013.00280

This article was submitted to the journal Frontiers in Cellular Neuroscience.

Copyright (c) 2013 Gerber, Privat and Perrin. This is an open-access article distributed under the terms of the Creative Commons Attribution License (CC BY). The use, distribution or reproduction in other forums is permitted, provided the original author(s) or licensor are credited and that the original publication in this journal is cited, in accordance with accepted academic practice. No use, distribution or reproduction is permitted which does not comply with these terms. 


\section{APPENDIX}

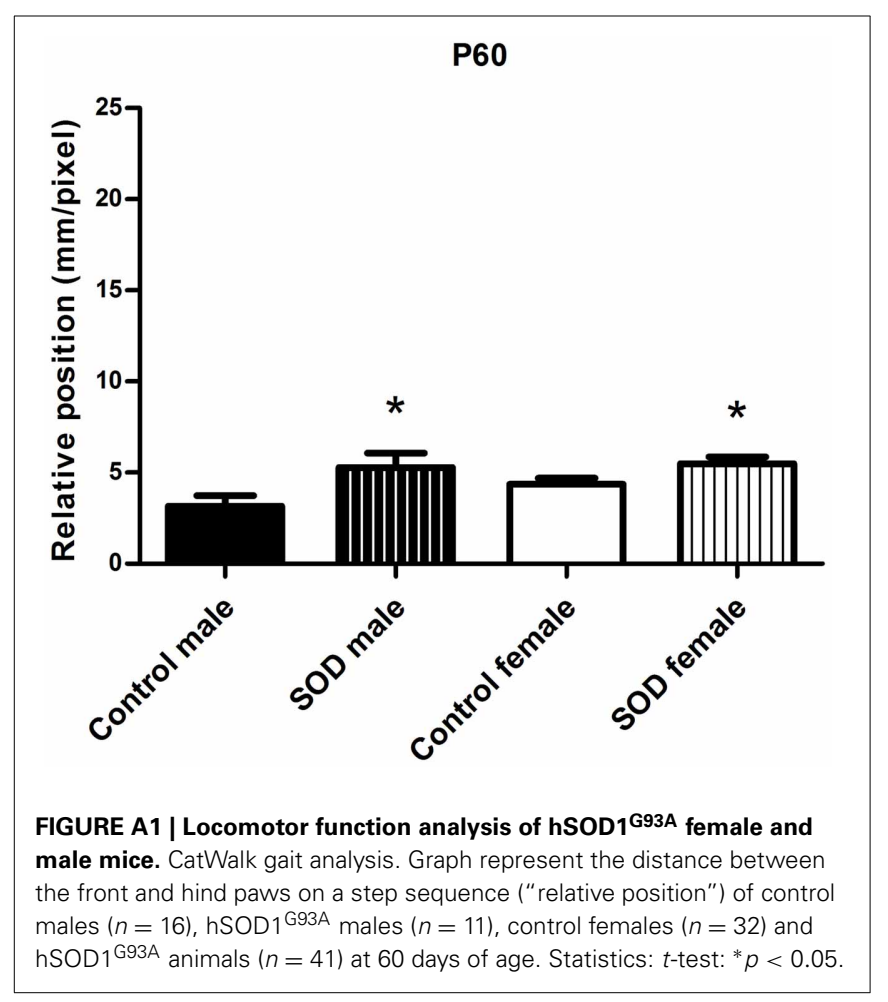

Table A1 | Frontlimb and hindlimb stride $(\mathrm{mm})$ of control mice at P60 $(n=22)$, Control $\mathrm{NaCl}$ at $\mathrm{P} 81(n=12), \mathrm{P} 109(n=13)$ and $\mathrm{P} 130$ ( $n=11$ ).

\begin{tabular}{lcccc}
\hline Colonne1 & P60 & P81 & P109 & P130 \\
\hline $\begin{array}{l}\text { Frontlimb } \\
\text { (mm) }\end{array}$ & $58.81 \pm 1.275$ & $59.00 \pm 1.317$ & $59.14 \pm 1.549$ & $61.48 \pm 2.053$ \\
$\begin{array}{l}\text { Hindlimb } \\
\text { (mm) }\end{array}$ & $59.28 \pm 1.393$ & $59.27 \pm 1.372$ & $59.14 \pm 1.507$ & $61.20 \pm 1.945$ \\
\hline
\end{tabular}

